\title{
How to manage and minimize food waste in the hotel industry: an exploratory research
}

\author{
Vera Amicarelli, Alina-Cerasela Aluculesei, Giovanni Lagioia, Rodica Pamfilie and \\ Christian Bux
}

(Information about the authors can be found at the end of this article.)

Received 21 January 2021 Revised 1 March 2021

27 April 2021

11 June 2021

Accepted 23 June 2021

(c) Vera Amicarelli,

Alina-Cerasela Aluculesei,

Giovanni Lagioia, Rodica

Pamfilie and Christian Bux

Published by Emerald

Publishing Limited. This article

is published under the Creative

Commons Attribution (CC BY

4.0) licence. Anyone may

reproduce, distribute, translate and create derivative works of this article (for both commercial and non-commercial purposes), subject to full attribution to the original publication and authors. The full terms of this licence may be seen at http://creativecommons.org/licences/by/4.0/ legalcode

The authors thank Rosa Basile and her team for the support during the research on food waste management within the hotel industry.

\begin{abstract}
Purpose - The hospitality industry is responsible for significant amounts of waste, more than one-third of which is food waste. Through the comparison between an Italian and a Romanian hotel, this paper aims to provide a better understanding of food waste management trends in the hotel industry as well as to highlight hotel kitchens and hotel food services weaknesses and opportunities to minimize food waste.

Design/methodology/approach - In-depth interviews, personal communication and observations were conducted to investigate food service planning, food procurement and food waste management, as well as to better comprehend current individuals' understanding and attitudes, infrastructures, legislative culture and opportunities either from the managerial and the employees' perspective. Data were analyzed according to a content analysis approach.

Findings - Three critical hot spots emerged from the analysis: prediction and check of guests' attendance, communication and transparency with local suppliers and among departments within the unit and purchasing frequency and perishable food provisioning. The accurate forecasting of the number of guests and their nationality is fundamental in avoiding food waste at food service, as well as implementing transparency and communication with local suppliers.

Originality/value - Although academia and authorities have recognized the crucial importance of food waste management, food waste research in the hotel industry remains under-researched. The present exploratory research contributes to the scarce empirical studies about hotels' food waste, giving theoretical and managerial recommendations for supporting further studies, highlighting the need for formal deals between hotels and local suppliers (food procurement), as well as the importance of foodnetworks that holds together companies, retailers and charities (food donation).
\end{abstract}

Keywords Food waste, Hospitality industry, Sustainability, Food procurement

Paper type Research paper

\section{Introduction}

In the European Union (EU), more than 88 million tons (Mt) of food waste is generated each year, representing approximately $20 \%$ of the food produced in the member states and accounting for over $€ 143 \mathrm{bn}$ in terms of associated financial costs (European Commission, 2019). To mitigate this phenomenon with highly social, economic and environmental impacts, the EU strengthened the role of sustainable consumption and production patterns in the food and beverage industry, focusing on the role of food waste and on food services (Beretta and Hellweg, 2019; Filimonau et al., 2019). Indeed, EU declared food waste as one of ten major indicators of the Circular Economy Monitoring Framework and targeted the decrease food losses as one of the Sustainable Development Goal's priorities, adopted in Agenda 2030, in terms of sustainable production and consumption. Habits or emotions still represents one of the major obstacles toward food waste minimization, highlighting the 
urgent need to involve consumers, governments and public authorities toward a more effective management of foodstuffs and waste deriving from production and domestic activities (van Geffen et al., 2019; Amicarelli et al., 2021). Further, the European Commission also initiated the EU Platform on Food Losses and Food Waste, accounting food loss and waste within the European Green Deal (Farm to Fork Strategy).

To this extend the hospitality industry, which represents a growing sector worldwide with a market value of over US\$600bn in 2018 (+28\% on 2014 market data) (Statista, 2020a), requires specific attention. With regards to the hotel industry, in terms of environmental impact, the International Hotel Environmental Iniviative (2002) estimated, on average, a daily amount of $0.8-1.2 \mathrm{~kg}$ of waste per guest, doubled on checkout days (Pirani and Arafat, 2014; Abdulredha et al., 2018). Although such quantity is mainly composed of solid waste (e.g. packaging), a considerable percentage (more than one-third) is represented by food waste, roughly $75 \%$ of which is still edible (Williams et al., 2011). In this context, an exploratory study has been conducted to gain a better understanding on food waste management trends in the hotel industry as well as to highlight hotel kitchens and hotel food services weaknesses and opportunities to minimize food waste, proposing a comparison between Italian and Romanian experiences. Contributing to the scarce empirical studies about hotels' food waste, the present research aims at giving theoretical and managerial recommendations either for supporting further studies, identifying preliminary implication or suggesting policy measures in the field of food waste management.

\section{Literature review and research background}

\subsection{Empirical and theoretical approaches on hotels' food waste management}

The hospitality industry, encompassing establishments such as canteens, elderly care hospitals, hotels, schools, restaurants and universities (Malefors et al., 2019), represents one of the major incomes and labor sources in $\mathrm{EU}$, and predictions on its sharp increase in future years impose several challenges to the economy, environment and society (Styles et al., 2019). Indeed, considering its practical importance, the topic raised the interest of scholars and academics in the field of food waste causes, disposal opportunities and techniques of valorization along the upstream stages of the food supply chain (Schanes et al., 2018; van Geffen et al., 2019). However, a limited number of studies have been conducted within hotel kitchens and hotel food services.

In terms of food waste quantification, Gretzel et al. (2019) recorded examples of reductions in pre- and post-consumption food waste, respectively kitchen and plate waste, mostly due to its impact on profitability and high costs of disposal. Then, considering a research conducted in a five-star hotel in Malta, Camilleri-Fenech et al. (2020) revealed that plate waste was on average of $0.21 \mathrm{~kg} /$ person at lunch and $0.16 \mathrm{~kg} /$ person at dinner, increasing to $0.48 \mathrm{~kg} /$ person during a buffet dinner. Nevertheless, the authors investigating the significant role of food planning practices in hotel kitchens (Leverenz et al., 2021), as well as food waste management alternatives in hotel food services (Gandhi et al., 2019), suggesting theoretical, managerial and political recommendations, are very few in number. Further, most of the studies were conducted in hotels located in Asia (Kasavan et al., 2019) or America (Okumus, 2019), while few researches concerned European realities. According to Okumus et al. (2020), the main hot spots for food waste are related to guest behaviors, preferences and attitudes and its limitation is complex due to the hospitality business's intrinsic unpredictability. As Tomaszewska et al. (2021) stated, the intervention on hotel staff's and guests' behaviors should be done through education. On the one hand, employees should be trained in the proper handling of food, while consumers should be informed on food waste consequences in terms of social, environmental and financial issues. Further, it seems crucial to investigate familiarity, knowledge and culinary traditions related to guests' nationality (Dolnicar and Juvan, 2019). Indeed, food waste at the 
hospitality level significantly depends on patrons' lack of knowledge on how to eat certain food items and lack of familiarity with certain types of food preparation.

In addition, literature has distinguished between managerial and consumers-side variables. At managerial level, the most investigated items regarded "inventory management and checks," "supplier agreement and relationship," "business models and concept," "food provisioning" and "accuracy in the prediction of the number of expected customers" (Dhir et al., 2020), while consumer-level ones focused on "perception," "attitudes and behavior" and "eating habits" (Papargyropoulou et al., 2016). As Tatàno et al. (2017) stated, food waste can be limited by promoting and using local, fresh and quality food, standardizing daily menus and improving cooking knowledge and experience, as well as limiting plate sizes. However, although such studies seem to address general paths and rooms for research, none of them explores food procurement, preparation and disposal in Italian or Romanian hotels.

\subsection{Italian and Romanian legislative background}

The hotels global occupancy rate, which is "the share of total rooms available which are occupied or rented at a given time," reaches its highest value in EU (72.4\%), where more than 6.3 million bedrooms are located. Among the EU-27 countries, Italy represents the highest quota, accounting for over 1 million bedrooms and similar accommodations (17\%) in 2018 (Istat, 2020; Statista, 2020a). In Romania, the total number of hotels was 1,600, with an accommodation capacity of 198,000 places and around 195,000 rooms (National Institute for Statistics - Romania, 2020). Table 1 illustrates Italian and Romanian hotelsrelated characteristics.

At country level, it is estimated that Italian avoided, reused, recycled or donated food amounts to over 90,000 $t$ (Banco Alimentare, 2019). Historically, the Italian experience started with Banco Alimentare in 1989, subsequently implemented by Law 460/1997 and Law 133/1999, and the first project was conducted in Northern Italy solely in 2003. Nevertheless, one of the first research conducted in the field of food donations, food safety and food security, was carried out in 2012 in Milan (Garrone et al., 2012). Although authorities suggested actions toward sustainable food consumption, Legge Gadda (GURI, 2016) has been implemented only in 2016, stating that hotels' stakeholders could donate unconsumed food to needy people and/or to feed animals or use for auto-composting. In Romania, food waste legislation resumes with Law 217/ 2016 that was completed on January 30, 2019 with the implementation rules. The law's main objective is to mitigate food waste in Romania and encourage food donation. Moreover, the companies that agree to donate food surpluses will benefit from tax

\section{Table 1 Italian and Romanian hospitality numbers in 2018}

\begin{tabular}{lcr} 
& Italy & Romania \\
\hline & 32,900 & 1,600 \\
Hotels & $1,090,000$ & 163,000 \\
Beds & $2,260,000$ & 198,000 \\
Total tourists & $123,000,000$ & $13,400,000$ \\
of which & & \\
Internal & $59,800,000$ & $10,700,000$ \\
Foreign & $63,200,000$ & $2,700,000$ \\
Tourists origin & Germany: less than 30\% & Rep. of Moldova: $20 \%$ \\
& France, U.K., U.S.: 6-6.5\% & Bulgaria: more than $14.5 \%$ \\
& China, Russia: less than 2.5\% & Ukraine: $14 \%$ \\
& Japan: $1 \%$ & Hungary: $12 \%$ \\
Source: Istat (2020), National Institute for Statistics - Romania (2020), Statista (2020b)
\end{tabular}


incentives. Food donation is the subject of several rules, such as the durability of food products or the type of food (Ministry of Agriculture and Rural Development, 2019). However, a specific law to apply in the hotel and restaurant sector has not been developed yet in Romania, remaining food waste at the discretion of each individual. At national level, the NGO sector created initiatives to mitigate food waste, such as Food Waste Romania Platform, the social shop Samaro (foodwaste.ro, 2020), Food Bank Bucharest and other similar projects international supermarket chains initiated (e.g. Lidl, Metro, Carrefour). However, the majority of initiatives are still concentrated in big cities like Bucharest, Cluj Napoca or Constanta, while less developed areas in Romania are insufficiently approached (Cantaragiu and Hadad, 2019).

\section{Research methodology}

In line with the European Commission (OJEU, 2019) which includes, among others, interviews as one of the five methodologies to investigate food waste along the entire food supply chain, the present exploratory research was based on in-depth interviews among managers, chefs and food service staff, joined to personal communications and observations inside the hotels. Then, considering the exploratory nature of the research, data have been analyzed according to a content analysis, being therefore possible to gain familiarity with the phenomenon in a flexible, inexpensive and unstructured way (Walsh, 2003; Erlingsson and Brysiewicz, 2017).

\subsection{Brief hotel description}

The Italian hotel (IT) is located in Marina of Palese, a coastal town in North of Bari in Apulia region. Its strategic position, 100 meters from the beach (Marina of Palese), $10 \mathrm{~km}$ far from Bari city center, $2 \mathrm{~km}$ from the airport (Karol Wojtyla international Airport) and its well connected with the central railway station and seaport make it perfect for business, cultural events and leisure stays. $\mathrm{H} 1$ is a four-star hotel, with 101 rooms, a restaurant, a cocktail bar, four conference halls and an outdoor pool, and it is not part of an international chain. The hotel staff is composed of two managers, 12 chefs and members of the kitchen staff and 15 members of the service staff.

The Romanian hotel $(\mathrm{RO})$ is a four-star accommodation unit located in the city center of Buzau, in the Southeast Region. The unit is located about $20 \mathrm{~km}$ away from the spa resort, Sarata Monteoru, and $110 \mathrm{~km}$ away from Bucharest, Romania's capital. The hotel has 120 rooms: 90 double rooms and 30 apartments, a spa center, four restaurants for large and small events and two conference halls, making it suitable for business and events. Further, it is not part of an international chain. In terms of human resources, the unit counts workers distinguished as follows: 3 managers, 15 among chefs and members of the kitchen staff, 20 members of the service staff. Being a national brand with its own internal rules, and being located in a city instead of in a resort, makes the results more accurate and helps researchers to better understand the food waste process.

\subsection{Data collection through in-depth interviews}

The investigation has been conducted from February 17 to March 2, 2020. According to Leray et al. (2016) and Kasavan et al. (2019), in-depth interview have been designed to investigate, among other logistics and administrative activities, food service planning, food procurement (i.e. food purchase) and food waste management, as well as to better comprehend current individuals' understanding and attitudes, infrastructures, legislative culture and opportunities either from the managerial and the employees' perspective. In line with Dhir et al. (2020), five main constructs have been considered to shape the in-depth interview, as follows:

VOL. 16 NO. 12022 INTERNATIONAL JOURNAL OF CULTURE, TOURISM AND HOSPITALITY RESEARCH $\mid$ PAGE 155 
1. inventory management and checks;

2. supplier agreement and relationships;

3. business models and concepts;

4. food provisioning; and

5. expected costumers' prediction.

The interview has been constructed on the basis of previous literature (Leray et al., 2016; Pirani and Arafat, 2016; Kasavan et al., 2019) and research methods handbooks (Brancato et al., 2006). Considering its aim of reaching either managers, chefs and kitchen staff or waiters and food service staff, the in-depth interview followed rules of feasibility, simplicity and generality, and contained 8 closed-ended questions and 12 open-ended ones. In addition, in line with Severt et al. (2008), the researchers maintained an open-ended, inductive and more loose approach due to the interpretative nature of the information needed. The closed-ended questions have been mainly addressed at understanding professional role, individuals' food waste knowledge and preliminary attitudes toward food preparation, servings and disposal. The open-ended ones, being crucial to comprehend more thoroughly food waste management within the hotels, have been focused on:

- food service planning (e.g. organization of the buffet or the à-la-carte menu);

- food procurement (e.g. food purchase frequency, procurement markets, products selection based on price or quality, selection of the quantity to buy); and

- food waste disposal, in terms of drivers, disposal routes and possible solution/ alternatives to disposal.

In addition, respondents were encouraged to self-assess the composition of food waste within each unit and propose personal outlooks to mitigate food waste. Then, to improve the knowledge on the reference context and understand more deeply some of the answers given during the interviews, further personal communication and observations have been conducted, aimed at investigating the hotel's historical background, the social context, the main food and beverage management practices, the level of communication among managers and employers and the guests' attitudes when eating (Charlebois et al., 2015). Specifically, 2 managers (i.e. general manager, food and beverage manager), 6 chefs (i.e. kitchen staff) and 10 waiters (i.e. service staff) have been interviewed from each unit. In terms of logistics, the main activities investigated concerned:

- purchase of raw materials and ingredients;

- food preparation;

- food service à la carte and/or buffet;

- food disposal of inedible food; and

- food disposal and/or recovery of unconsumed and still edible food donation (Figure 1).

\subsection{Data analysis}

Data collected through in-depth interviews have been thoroughly analyzed through a content analysis. Although it seems not to exists a homogeneous understanding of such a methodology, and several definitions have been provided by different researchers (Kohlbacher, 2006), the content analysis could be described as "the study of recorded human communications" (Babbie, 2020), whose aim is to detect "underlying themes in the materials being analyzed" (Bryman, 1992) and not in terms of quantity, amount, intensity or frequency (Denzin and Lincoln, 2005). As stated by Walsh (2003), content analysis findings have the chance to identify the not-so-obvious perspectives inside in-depth interviews, 


\section{Figure 1 Main processes investigated}

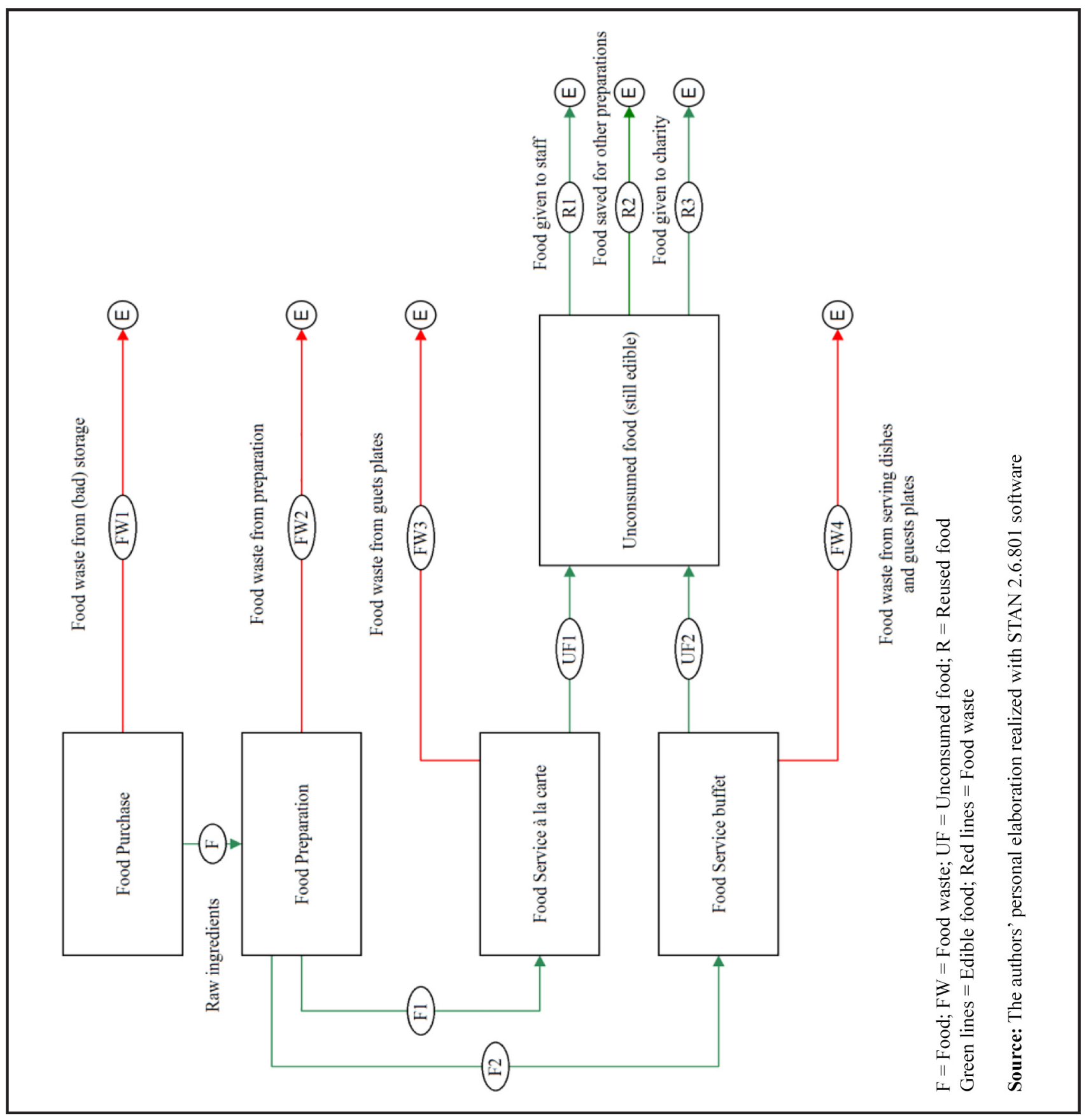


becoming the potential ground break for both academics and practitioners and playing a critical role in creating new theories. Indeed, it has been successfully applied in several research areas (e.g. social sciences, medicine, economics) and specifically in tourism and hospitality, as reported by Camprubì and Coromina (2016), Boo and Busser (2018) and Andreu et al. (2020). Considering that the content analysis concentrates on recorded communication (i.e. transcripts of in-depth interviews), the present research investigated respondents' interviews step-by-step, as proposed by Mayring (2000), Bengtsson (2016) and Erlingsson and Brysiewicz (2017). Therefore, systematic rules of procedure, devising the material into content analytical units, have been applied as follows:

- summary, reducing material into meaning units and preserving the essential content (e.g., paraphrased, generalized or reduced interviews);

- explication (or categorization), clarifying and annotating the keywords; and

- interpretation, in a process which starts from initial theory and arrives to interpretation.

Data have been elaborated using Microsoft Excel spreadsheets. Figure 2 illustrates the research process from data collection to interpretation.

\section{Results}

In-depth interviews, according to the content analysis, have been systematically investigated in a transparent and rigorous way, as shown in the example provided in Table 2.

Keywords resulting from the content analysis are illustrated in Figure 3. The graphs show the main results with reference to:

- managers;

\section{Figure 2 Research process from data collection to interpretation}

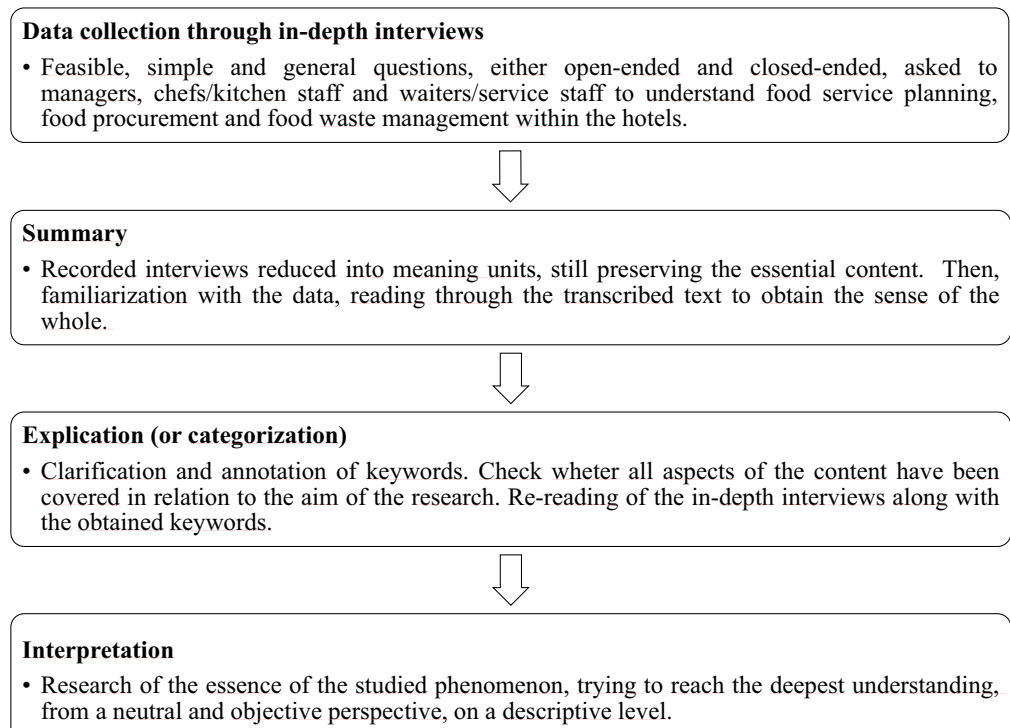

from a neutral and objective perspective, on a descriptive level.

(Personal elaboration by the authors) 
Table 2 Example of content analysis, from snippet to keyword

\begin{tabular}{lll} 
Snippet & Meaning unit & Keywords \\
\hline $\begin{array}{lll}\text { If guests are widely composed by English or } \\
\text { German people, croissants are not needed }\end{array}$ & $\begin{array}{l}\text { English or German prefer salty } \\
\text { breakfast, while Italians prefer } \\
\text { but eggs and bacon are. On the contrary, } \\
\text { when Italians book for breakfast, quantity is }\end{array}$ & Nationality \\
more important than quality, according to & Nationality is essential & \\
Italians food culture. Nationality is essential & & \\
There is a strong communication with some & Communication with local & Local, dealers \\
$\begin{array}{l}\text { dealers and local markets. If they have a } \\
\text { huge quantity of fresh fruit and vegetables, }\end{array}$ & $\begin{array}{l}\text { market dealers. Financial } \\
\text { savings avoiding food waste }\end{array}$ & \\
they ask us to pick it up with a particular & & Donation \\
discount avoiding useless waste & Leftovers donation to the staff & \\
Leftovers are principally donated to the & & \\
staff. Even if some of them are not on a & & \\
working shift, we call them to ensure that & & \\
food is not thrown away & & \\
(Personal elaboration by the authors) & &
\end{tabular}

- chefs (kitchen staff); and

- waiters (service staff), highlighting differences and similarities among the units.

Indeed, it results that keywords such as "self-production" and "local" have been mainly used by IT managers, while "cash-and-carries" and "software" by RO ones. The same applies to IT chefs, which have mainly adopted keywords like "dealers" and "agreements" rather than "supermarkets" and "composting", as RO chefs did. In terms of waiters/service staff, IT and RO employees have shown a certain similarity resulting in keywords like "fruits", "vegetables" and "pastries", as well as "nationality" and "age".

\subsection{Results on the side of food service planning}

In terms of internal food waste policy, IT managers personally take care of meals preparation, coordinating both the administrative department and the kitchen staff. Indeed, their management is founded on three main pillars:

1. control of guests' attendance;

2. efficient communication between departments; and

3. perishable goods storage and management.

According to food service planning, breakfast and dinner are served as a buffet, while lunch is à-la-carte. In the buffet organization, the main steps regard (manually) quantifying guests and analyzing their nationality, since the quality/quantity of needed food mostly depends on it. Moreover, in terms of food supply, IT managers tent to maximize selfproduction of food (e.g. croissants, cakes, jam or bread are homemade), implementing the "farm-to-fork" approaches to reduce food waste amounts and associated environmental impacts and financial costs. RO experience follows similar trends. Indeed, both managers and chefs consider food waste policy, focusing their strategy on waste collection according to the national rules, highlighting the staff's role in adopting sustainable behaviors. Indeed, the main obstacles in decreasing food waste are the lack of reservation forecast - which requires introducing a particular software and hiring skilled employees - and the lack of logistic service to support food waste. Furthermore, serving breakfast as a buffet, and being aware that such service is more food waste generating, the unit makes substantial efforts by analyzing the number of guests and their nationality, the season and their (eventual) special requests. Moreover, management is also concerned about the behavior changes in terms 
Figure 3 Keywords share among IT - RO managers, chefs and service staff
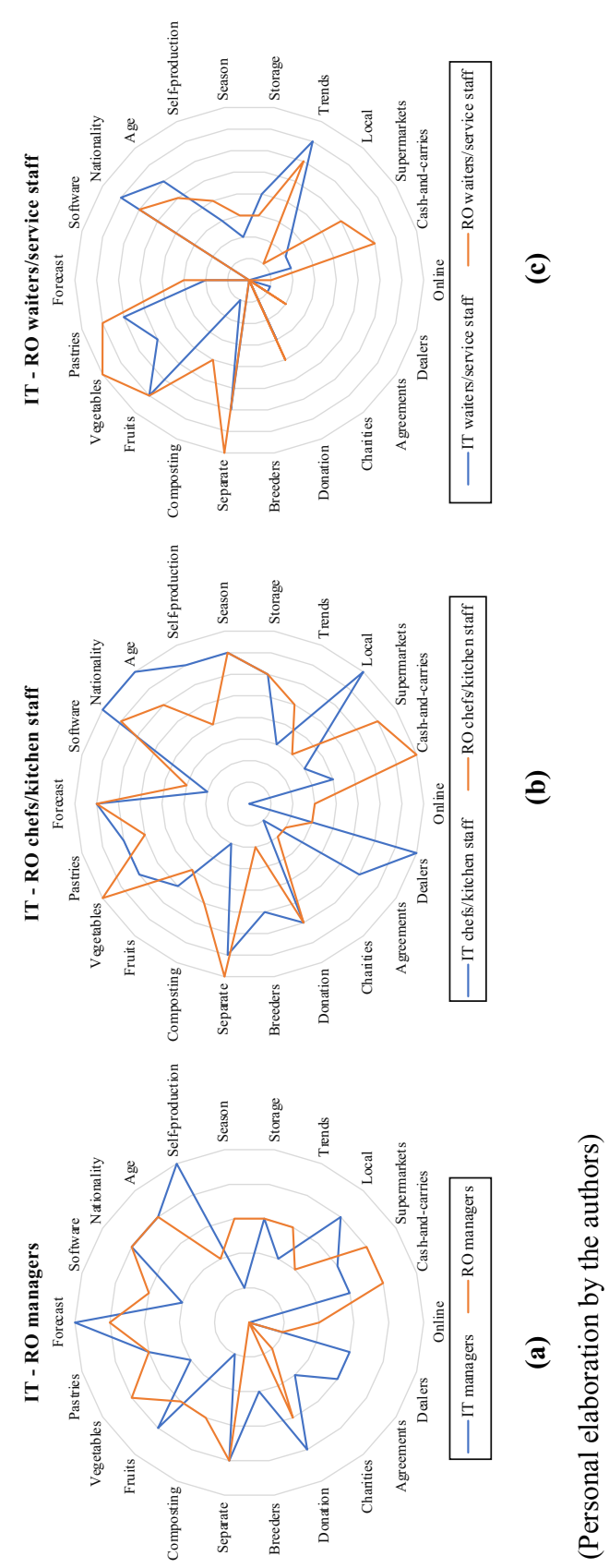
of food consumption (e.g. food trends) and food availability in local markets, trying to adjust provisioning quantities as soon as possible.

\subsection{Results on the side of food purchase}

According to food purchase, Italians are more likely to buy food at cash and carries and fresh local markets on a daily basis, strengthening informal agreements with dealers that have huge quantities of fresh fruit and vegetables and offer them particular discounts to avoid useless waste. Therefore, IT has created a well-articulated network with local fruit and vegetable retailers, implementing a so-called industrial symbiosis. Managers and dealers work together to prevent unsold but still edible product from becoming waste, transforming fresh fruit into jam and increasing (if possible) the offer of fruits and vegetables in the menu. In this way, food waste is avoided at marketplaces with related monetary benefits for both actors: sellers, who are not forced to throw away food, losing their revenue, and hotel managers, who buy food with an economic advantage. On the other side, Romanians purchase raw ingredients and food primarily from cash and carries units, supermarkets, online and collaborates with HoReCa (Hotels, Restaurants and Catering) suppliers daily. They self-prepare food inside the unit, both from raw ingredients and edible unconsumed food, but have declared no particular interaction with local markets or specific dealers.

\subsection{Results on the side of food waste management}

At the moment of disposal, IT managers pay attention to the difference between edible (for human donation) and inedible food (mainly for animal feed). The south of Italy's historical background justifies this knowledge: Until the 1970s, IT was located in a peripheral area of the municipality of Bari, surrounded by areas intended for agriculture and animal breeding. Nowadays, after a sharp urbanization process, urban areas have spread, replacing lands and pastures all around the hotel. In the case of food waste at preparation, managers give priority to animal feed (personal knowledge of local breeders) and later to separate waste. If food waste is generated at consumption, leftovers from buffets are mainly donated to the staff and/or used for other meals' preparation. Indeed, food waste from guests' plates is mandatorily destined to a separate collection, even if hoteliers are still skeptical toward it they do not strongly believe in the efficiency of collection services and often, due to such skepticism, are not particularly focused on wasting differentiation. On the other side, RO managers and kitchen staff understand the difference between edible and inedible food and take actions following the national legislation. At the moment of disposal, they give priority to separate collection, then they provide the edible food to the staff and, if possible, use edible food to prepare other dishes. Regarding the inedible fractions, they are mainly used for compost.

\subsection{Results on the side of the kitchen and service staff}

According to waiters and food service staff, buffet service appears more responsible for food waste than à-la-carte one, as guests' behavior is generally unsustainable/unaware toward the issue. The principal typologies of food waste detected are fruits, vegetables and pastries. In addition, Italian families with children seems to be the less virtuous toward the issue, while old-aged people, foreign guests and business travelers are the most virtuous ones. In terms of opportunities, staff considers an awareness campaign as a good solution to mitigate food waste. In this way, the hotel would inform guests about the consequences of food waste, stressing the necessity of pursuing sustainable behavior (Kallbekken and Sælen, 2013; Chen and Jai, 2018). Moreover, kitchen and food service staff propose several actions to mitigate food waste that employees can adopt. Some examples include disposing raw ingredients according to the specifications on the label. Also, the ingredients should be stored depending on the level of freshness: Food bought more recently should

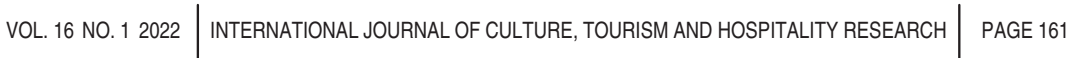


be placed toward the back of the fridge. Another idea is to freeze food every time it is suitable.

Last, both managers and service staff complain about a huge number of guests' unsustainable behavior and the lack of awareness/sensitization toward the issue. As a suggestion, they propose:

- implementing an awareness plan within and outside the units; and

- introducing policies that regulate the withdrawal of unconsumed food for human consumption and animal feed.

\section{Discussion}

\subsection{Driving forces and obstacles}

From the moment food enters the consumption stage (as raw ingredients) until the moment it exits (as leftovers and/or waste), little is known about what happens. Generally, food preparation, food service and unconsumed food management are intended as a single process, but this is not true: It is important to understand where food is bought, the purchasing frequency, the way food is prepared and consumed and the techniques adopted to dispose and/or reuse what has become waste. This means that the single process, the so-called "final consumption," must be disaggregated among single activities (Marthinsen et al., 2012). As previously discussed by academics (Silvennoinen et al., 2015), these activities vary from one unit to another and depend on proper internal organization and management, nationality, social and cultural heritage and other subjective and objective variables (i.e. level of integration, communication and transparency within the different unit departments, innovation and technologies adopted, knowledge of legislative framework).

According to the exploratory results, three main critical steps of the food waste issue emerged, as follows:

1. predicting and checking guests' attendance;

2. communication and transparency with local suppliers and among departments within the unit; and

3. purchasing frequency and perishable food provisioning.

In line with literature (Tatàno et al., 2017; Principato et al., 2018), accurately forecasting of the number of guests and their nationality seems to be fundamental in avoiding food waste at food service as well as implementing transparency and communication outside the unit through efficient communication between local fresh market suppliers and hotels (or restaurants) (Kilibarda et al., 2019). Indeed, informal deals between hotels and local suppliers should be substituted by formal agreements, as the creation of preferential distribution channels could avoid food waste at distribution stage through selling perishable products at a lower price. Further, the paradigm of transparent and clear communication must also be implemented between chefs, waiters and managers, considering that managers, who personally take care of the kitchen and are aware of food waste issue, who coordinate more than one department and know exactly how to prepare and to dispose food, are more likely to control and correct food waste attitudes, converging toward more sustainable procedures in a shorter time. Though, several obstacles should be removed, such as the lack of a specific software to calculate the "number of guests-food required" ratio, the lack in separate collection infrastructures - of which some managers are skeptical - and the lack of an awareness campaign addressed to guests, as suggested by Chinese managers (Filimonau et al., 2020). 
In terms of future perspectives on food waste management, results from the analysis are quite similar to those already presented by previous authors. Good practical examples refer to the introduction of tasting plates, which allows guests - especially children - to taste small portions of food. Indeed, as stated by Juvan et al. (2018), massive portions containing local food (usually not familiar to tourists) cause much waste. Other possible measures could regard the reduction of the buffet rooms, considering that smaller areas are more likely to be controlled, or the implementation of specialized software to better estimate the quantities needed (currently carried out with rudimentary management systems). Further, in terms of food leftovers management, both managers from Italy and Romania have proposed introducing an online platform for donating food both for human consumption or for animals and suggested promoting awareness campaigns within and outside each unit (at the local, regional and national levels). One possible option, as suggested by Linh (2018), could be the introduction of web-based and mobile platforms intended to recover food excess and prevent them from being thrown away. In addition, local authorities should stress the need for formal agreements among hotels and charities, considering that most of the solutions to reduce food waste in the hospitality industry pass through the private sector (e.g. online platforms such as TooGoodToGo) (Alaimo et al., 2021).

\subsection{Theoretical prospects, limitations and future research}

Under a theoretical perspective, the exploratory research contributes to the scarce empirical studies about hotels' food waste, giving theoretical and managerial recommendations either for supporting further studies, identifying preliminary implication or suggesting policy measures. Indeed, it confirms past trends and adds new insights, stressing the urgence for support in the creation of formal agreements either between hotels, local suppliers (in terms of food procurement) and charities (in terms of food donation). However, one of the main limits of the present research is represented by the numbers of units investigated, which do not guarantee generalizations at sector level but still provides essential highlights for public authorities, academics and private stakeholders. To this extent, further research is intended to investigate guests' perspective, highlighting the role of consumers' awareness, attitudes and behavior toward food waste minimization in the hotel industry. In addition, future studies will include a larger number of hotels with different characteristics and located in other parts regions of Italy and Romania.

\section{Conclusions}

In conclusion, the hotel sector has significant opportunities to reduce the amount of food waste it produces, but several efforts are required both by single units and public authorities. Indeed, the present research shows that either Italian and Romanian managers, chefs and service staff are aware of food waste issues under financial, social and environmental perspective, and are continuously looking for solutions, but face every day several obstacles toward its minimization. According to those opportunities outside-the-unit, it seems essential to enhance formal deals between hotels and local suppliers, trying to create preferential distribution channels which could generate advantages from the side of food service and from that of food distribution. Further, formal agreements should be underwritten between hotels and foodbanks, with the aim of generating a food-network that holds together companies, retailers and charities. In terms of solutions inside-the-unit, several efforts are needed to improve processes at administrative, kitchen and service level. Indeed, considering the importance of involving technology in the hotel sector, units should have more support from national authorities both in terms of funding and consultancy. It is essential the introduction of dedicated software that can predict the quantities of required raw ingredients on the basis of the number of guests and their nationality. Limiting the quantities of unconsumed food needs more than traditional analyses, and digitalization in this regard can represent an actual solution.

VOL. 16 NO. 12022 INTERNATIONAL JOURNAL OF CULTURE, TOURISM AND HOSPITALITY RESEARCH $\mid$ PAGE 163 


\section{References}

Abdulredha, M., Al Khaddar, R., Jordan, D., Kot, P., Abdulridha, A. and Hashim, K. (2018), "Estimating solid waste generation by hospitality industry during major festivals: a quantification model based on multiple regression", Waste Management, Vol. 77, pp. 388-400.

Alaimo, L.S., Fiore, M. and Galati, A. (2021), "Measuring consumers' level of satisfaction for online food shopping during COVID-19 in Italy using POSETs", Socio-Economic Planning Sciences, p. 101064.

Amicarelli, V., Tricase, C., Spada, A. and Bux, C. (2021), "Households' food waste behavior at local scale: a cluster analysis after the COVID-19 lockdown”, Sustainability, Vol. 13 No. 6, pp. 3283.

Andreu, L., Bigne, E., Amaro, S. and Palomo, J. (2020), "Airbnb research: an analysis in tourism and hospitality journals", International Journal of Culture, Tourism and Hospitality Research, Vol. 14 No. 1, pp. 2-20.

Babbie, E. (2020), The Practice of Social Research, 15th ed., Cengage Learning, Boston.

Banco Alimentare (2019), "Risultati”, available at: www.bancoalimentare.it/it (accessed 19 December 2020).

Bengtsson, M. (2016), "How to plan and perform a qualitative study using content analysis", NursingPlus Open, Vol. 2, pp. 8-14.

Beretta, C. and Hellweg, S. (2019), "Potential environmental benefits from food waste prevention in the food service sector", Resources, Conservation and Recycling, Vol. 147, pp. 169-178.

Boo, S. and Busser, J.A. (2018), "Meeting planners' online reviews of destination hotels: a twofold content analysis approach", Tourism Management, Vol. 66, pp. 287-301.

Brancato, G., Macchia, S., Murgia, M., Signore, M., Simeoni, G., Blanke, K., Korner, T., Nummergut, A., Lima, P., Paulino, R. and Hoffmeyer-Zlotnik, J.H.P. (2006), Handbook of Recommended Practices for Questionnaire Development and Testing in the European Statistical System, Istat, Rome.

Bryman, A. (1992), "Quantitative and qualitative research: further reflections on their integration", in Brannen, J. (Ed.), Mixing Methods: qualitative and Quantitative Research, Avebury, Brookfield, pp. 57-78.

Camilleri-Fenech, M., Oliver, J., Farreny, R. and Gabarrell, X. (2020), "A snapshot of solid waste generation in the hospitality industry", Sustainable Production and Consumption, Vol. 21, pp. 104-119.

Camprubì, R. and Coromina, R. (2016), "Content analysis in tourism research", Tourism Management Perspectives, Vol. 18, pp. 134-140.

Cantaragiu, R. and Hadad, S. (2019), "Food waste and rural tourism - a Romanian perspective", Ovidius University Annals, Economic Sciences Series, Vol. 19 No. 1, pp. 152-160.

Charlebois, S., Creedy, A. and von Massow, M. (2015), "Back of house" - focused study on food waste in fine dining: the case of delish restaurants", International Journal of Culture, Tourism and Hospitality Research, Vol. 9 No. 3, pp. 278-291.

Chen, H.S. and Jai, T.C. (2018), "Waste less, enjoy more: forming a messaging campaign and reducing food waste in restaurants", Journal of Quality Assurance in Hospitality \& Tourism, Vol. 19 No. 4, pp. 495-520.

Denzin, N.K. and Lincoln, Y.S. (2005), "Introduction: the discipline and practice of qualitative research", in Denzin, N.K. and Lincoln, Y.S. (Eds), The Sage Handbook of Qualitative Research, Sage Publications, pp. 1-32.

Dhir, A., Talwar, S., Kaur, P. and Malibari, A. (2020), "Food waste in hospitality and food services: a systematic literature review and framework development approach", Journal of Cleaner Production, Vol. 270, p. 122861.

Dolnicar, S. and Juvan, E. (2019), "Drivers of plate waste: a mini theory of action based on staff observations (research note)", Annals of Tourism Research, Vol. 78, p. 102731.

Erlingsson, C. and Brysiewicz, P. (2017), "A hands-on guide to doing content analysis", African Journal of Emergency Medicine, Vol. 7 No. 3, pp. 93-99.

European Commission (2019), "Q\&A. Frequently asked questions: reducing food waste in the EU", available at: https://ec.europa.eu/commission/presscorner/detail/en/QANDA_19_6706 (accessed 20 December 2020).

Filimonau, V., Krivcova, M. and Pettit, F. (2019), "An exploratory study of managerial approaches to food waste mitigation in coffee shops", International Journal of Hospitality Management, Vol. 76, pp. 48-57.

Filimonau, V., Zhang, H. and Wang, L.E. (2020), "Food waste management in shanghai full-service restaurants: a senior managers' perspective", Journal of Cleaner Production, Vol. 258, pp. 120975. 
foodwaste.ro (2020), "About the platform", available at: http://foodwaste.ro/platforma/ (accessed 19 December 2020).

Gandhi, P., Kumar, S., Paritosh, K., Pareek, N. and Vivekanand, V. (2019), "Hotel generated food waste and its biogas potential: a case study of Jaipur city, India", Waste and Biomass Valorization, Vol. 10 No. 6 , pp. 1459-1468.

Garrone, P.Melacini, M.Perego, A. and Pollo, M. (2012), "Food waste reduction: empirical findings from the Italian food supply chain", available at: https://ssrn.com/abstract=2109587 (accessed 21 April 2021).

Gretzel, U., Murphy, J., Pesonen, J. and Blanton, C. (2019), "Food waste in tourist households: a perspective article", Tourism Review, Vol. 75 No. 1, pp. 235-238.

GURI (Gazzetta Ufficiale Repubblica Italiana) (2016), LEGGE 19 Agosto 2016, n. 166, Disposizioni Concernenti la Donazione e la Distribuzione di Prodotti Alimentari e Farmaceutici a Fini di Solidarietà Sociale e per la Limitazione Degli Sprechi, Serie Generale n. 202 del 30-08-2016.

International Hotel Environmental Iniviative (2002), "Hotels case: Community action and responsibility for the environment", IHEI, London, England.

Istat (2020), "Esercizi ricettivi: capacità degli esercizi ricettivi per movimento dei clienti negli esercizi ricettivi per tipo di esercizio - mensili - com", available at: http://dati.istat.it/Index.aspx?Queryld=7053 (accessed 19 December 2020).

Juvan, E., Grün, B. and Dolnicar, S. (2018), "Biting off more than they can chew: food waste at hotel breakfast buffets", Journal of Travel Research, Vol. 57 No. 2, pp. 232-242.

Kallbekken, S. and Sælen, H. (2013), "Nudging' hotel guests to reduce food waste as a win-win environmental measure", Economics Letters, Vol. 119 No. 3, pp. 325-327.

Kasavan, S., Mohamed, S.F. and Halim, S.A. (2019), "Drivers of food waste generation: case study of island-based hotels in Langkawi, Malaysia", Waste Management, Vol. 91, pp. 72-79.

Kilibarda, N., Djokovic, F. and Suzic, R. (2019), "Food waste management-reducing and managing food waste in hospitality", Meat Technology, Vol. 60 No. 2, pp. 134-142.

Leray, L., Sahakian, M. and Erkman, S. (2016), "Understanding household food metabolism: relating microlevel material flow analysis to consumption pratices", Journal of Cleaner Production, Vol. 125, pp. 44-55.

Leverenz, D., Hafner, G., Moussawel, S., Kranert, M., Goossens, Y. and Schmidt, T. (2021), "Reducing food waste in hotel kitchens based on self-reported data", Industrial Marketing Management, Vol. 93, pp. 617-627.

Linh, N.K. (2018), Food Waste Management in the Hospitality Industry Case Study: Clarion Hotel Helsinki. Haaga-Helia, University of Applied Sciences, Helsinki, Finland.

Malefors, C., Callewaert, P., Hansson, P.A., Hartikainen, H., Pietiläinen, O., Strid, I., Strotmann, C. and Eriksson, M. (2019), "Towards a baseline for Food-Waste quantification in the hospitality SectorQuantities and data processing criteria", Sustainability, Vol. 11 No. 13, p. 3541.

Marthinsen, J., Sundt, P., Kaysen, O. and Kirkevaag, K. (2012), "Prevention of food waste in reastaurants, hotels, canteens and catering", Nordic Council of Ministers, Copenaghen, Denmark.

Mayring, P. (2000), "Qualitative content analysis", Forum: Qualitative Social Research, Vol. 1 No. 2, pp. 1-20.

Ministry of Agriculture and Rural Development (2019), "Reglementări privind risipa alimentară", available at: www.madr.ro/comunicare/4948-reglementari-privind-risipa-alimentara.html (accessed 19 December 2020).

National Institute for Statistics - Romania (2020), "Tourism series", available at: http://statistici.insse.ro: 8077/tempo-online/\#/pages/tables/insse-table (accessed 21 December 2020).

OJEU (Official Journal of the European Union (2019), "Commission delegated decision (EU) 2019/1597 of 3 may 2019", available at: https://eur-lex.europa.eu/legal-content/EN/TXT/?uri=OJ:L:2019:248:TOC (accessed 17 December 2020).

Okumus, B. (2019), "How do hotels manage food waste? Evidence from hotels in Orlando, Florida", Journal of Hospitality Marketing \& Management, Vol. 29 No. 3, pp. 291-309.

Okumus, B., Taheri, B., Giritlioglu, I. and Gannon, M. (2020), "Tackling food waste in all-inclusive resort hotels", International Journal of Hospitality Management, Vol. 88, p. 102543.

Papargyropoulou, E., Wright, N., Lozano, R., Steinberger, J., Padfield, R. and Ujang, Z. (2016), "Conceptual framework for the study of food waste generation and prevention in the hospitality sector", Waste Management, Vol. 49, pp. 326-336. 
Pirani, S.I. and Arafat, H. (2014), "Solid waste management in the hospitality industry: a review", Journal of Environmental Management, Vol. 146, pp. 320-336.

Pirani, S.I. and Arafat, H. (2016), "Reduction of food waste generation in the hospitality industry", Journal of Cleaner Production, Vol. 132, pp. 129-145.

Principato, L., Pratesi, C.A. and Secondi, L. (2018), "Towards zero waste: an exploratory study on restaurant managers", International Journal of Hospitality Management, Vol. 74, pp. 130-137.

Schanes, K.,; Dobernig, K. and GöZet, B. (2018), "Food waste matters - a systematic review of household food waste practices and their policy implications", Journal of Cleaner Production, Vol. 182, pp. 978-991.

Severt, D., Aiello, T., Elswick, S. and Cyr, C. (2008), "Hospitality in hospitals?", International Journal of Contemporary Hospitality Management, Vol. 20 No. 6, pp. 664-678.

Silvennoinen, K., Heikkilä, L., Katajajuuri, J.M. and Reinikainen, A. (2015), "Food waste volume and origin: case studies in the Finnish food service sector", Waste Management, Vol. 46, pp. 140-145.

Statista (2020a), "Hotels", available at: www.statista.com/outlook/267/100/hotels/worldwide (accessed 16 December 2020).

Statista (2020b), "Number of bedrooms in hotels and similar accomodation in Romania from 2007 to 2019", available at: www.statista.com/statistics/613866/number-of-hotel-bedrooms-romania/ (accessed 16 December 2020).

Styles, D., Schönberger, H. and Galvez Martos, J.L. (2019), Best Environmental Management Practice in the Tourism Sector, European Commission - Joint Research Centre, Seville.

Tatàno, F., Caramiello, C., Paolini, T. and Tripolone, L. (2017), "Generation and collection of restaurant waste: characterization and evaluation at a case study in Italy", Waste Management, Vol. 61, pp. 423-442.

Tomaszewska, M., Bilska, B., Tul-Krzyszczuk, A. and Kołożyn-Krajewska, D. (2021), "Estimation of the scale of food waste in hotel food Services-A case study", Sustainability, Vol. 13 No. 1, p. 421.

van Geffen, L., van Herpen, E. and van Trijp, H. (2019), "Household food waste - how to avoid it? An integrative review", in Närvänen, E., Mesiranta, N., Mattila, M. and Heikkinen, A. (Eds), Food Waste Management, Palgrave Macmillan, Cham.

Walsh (2003), "Qualitative research: advancing the science and practice of hospitality", Cornell Hotel and Restaurant Administration Quarterly, April 2003, pp. 66-74.

Williams, P., Leach, B., Christensen, K., Armstron, G.D., Hawkins, R.P., Lane, A.J.G. and Scholes, P. (2011), The Composition of Waste Disposed of by the UK Hospitality Industry, Waste and Resources Action Programme, London, Report RES093-001.

\section{Further reading}

International Hotels Environment Initiative (2002), Hotels Care: Community Action and Responsibility for the Environment, IHEI, London, England.

Kohlbacker, F. (2006), "The use of qualitative content analysis in case study research", Forum: Qualitative Social Research, Vol. 7 No. 1, p. 21.

\section{Author affiliations}

Vera Amicarelli is based at the Department of Economics, Management and Business Law, University of Bari Aldo Moro, Bari, Italy

Alina-Cerasela Aluculesei is based at Institute for World Economy, Romanian Academy, Bucharest, Romania

Giovanni Lagioia is based at the Department of Economics, Management and Business Law, University of Bari Aldo Moro, Bari, Italy

Rodica Pamfilie is based at the Faculty of Business and Tourism, Bucharest University of Economic Studies, Bucharest, Romania 
Christian Bux is based at the Department of Economics, Management and Business Law, University of Bari Aldo Moro, Bari, Italy

\begin{abstract}
About the authors
Vera Amicarelli, PhD in Commodity Science, is an Associate Professor at Department of Economics, Management and Business Law DEMDI Commodities Science section at the University of Bari Aldo Moro, Italy. She teaches Industrial Ecology, Quality theory and technique and Resource and waste management. She is the author of more than 75 papers published on scientific journals and academic volumes. Her current research interests are focused on Material Flow Analysis, Environmental Indicators such as Water and Carbon Footprint and Circular Economy. Her main academic activities are related to Erasmus+ exchange program - she is department delegate and coordinator for several agreements with foreign universities - and she is in the working group for DEMDI course of study qualification. Since 2018, she is member of ICESP (Italian Circular Economy Stakeholders Platform) and form 1998 of Italian Commodity Science Academy (AISME).

Alina-Cerasela Aluculesei, $\mathrm{PhD}$ in Business Administration and Tourism, is a Scientific Researcher at the Institute for World Economy from the Romanian Academy. She is the Editor in Chief and Owner of the Junior Scientific Researcher Journal. Her current research interests are focused on wellness and health tourism, Romanian SPAS, food loss and food waste minimization, education on climate change. She is author of more ten papers published on scientific journals and academic volumes.
\end{abstract}

Giovanni Lagioia, PhD in Commodity Science, is a Full Professor of Commodity Science, Commodity Science of Natural Resources and Environmental Certification Systems at the Department of Economics, Management and Business Law of the University of Bari, Italy and at Catholic University Our Lady of Good Counsel, Faculty of Economics, Tirana, Albania. He is author of more than 150 papers published on the main scientific journals and academic volumes. His principal field of study regards impacts of commodity production and consumption and environmental management systems. Since 2018, he is Director of the Department of Economics, Management and Business Law, University of Bari Aldo Moro, Italy.

Rodica Pamfilie, PhD, is a Full Professor of Commodity Science and Management of Innovation and Design at the Bucharest University of Economic Studies, Faculty of Business and Tourism. She is coordination of the educational and scientifical activities in the Faculty of Business and Tourism, Business administration (in Commerce, Tourism and Services, Study of commodities and Quality Management) field. She is coordinator of PhD thesis, of dissertations for master's programs and for graduation degrees. She is the Vice-president of the International Association of Commodity Science and Quality Management (IGWT).

Christian Bux is a PhD student in Economics and Management at University of Bari Aldo Moro, Department of Economics, Management and Business Law. His main field of interest is the relationship between natural resources, commodity production/consumption and environmental management systems. His doctoral research project regards food loss and waste management, circular economy and material flow analysis. He is author of more than ten papers published on scientific journals and academic volumes. Christian Bux is the corresponding author and can be contacted at: christian.bux@uniba.it

For instructions on how to order reprints of this article, please visit our website:

www.emeraldgrouppublishing.com/licensing/reprints.htm

Or contact us for further details: permissions@emeraldinsight.com 